\title{
Research on the Mode of Cultivating Innovative Talents Based on the Integration of Industry-University-Research
}

\author{
Chuanlin Huang ${ }^{1, a^{*}}$, Yao $\mathrm{Li}^{1, \mathrm{~b}}$ and Shuang Gao ${ }^{1, \mathrm{c}}$ \\ ${ }^{1}$ No. 8, software park road, Dalian, Liaoning, China \\ ahuangchuanlin@neusoft.edu.cn, bliyao@neusoft.edu.cn, cgaoshuang@neusoft.edu.cn
}

Keywords: ERP; Informatization; Talent training; Industry-university-research

\begin{abstract}
With the rapid development of information science and technology, there are also serious problems in the supply and demand of applied talents between informatization enterprises and higher education schools. Industry-university-research cooperation has become the fundamental solution to the problem. Based on the status quo and characteristics of ERP informatization talents, this paper studies the training mode of information innovation talents based on the integration of industry-university-research, establishes the innovation system of talent ability for ERP industry, and the integration of industry-university-research.
\end{abstract}

\section{Current status of information talent development}

The 21 st century is an era of rapid development of information science and technology ${ }^{[1]}$. Informationization is a general trend of economic and social development in the world at present. At present, the demand for information management personnel mainly concentrated in three directions: computer, management, information services. From the talent market, information management professionals engaged in enterprise information research and development advantages did not show up, and even to a certain extent, weaker than computer science students, many graduates there is professional knowledge, but not sophisticated, only to understand the basis Theory and do not have the ability to implement the application of information technology, thus further exacerbating the current situation of short supply of information technology professionals.

Enterprise Resource Planning (ERP) refers to the management platform based on information technology and based on systematic management thought, which provides decision-making operation means for decision makers and employees ${ }^{[2]}$. ERP system integrates information technology and advanced management ideas into a modern enterprise's operation mode, reflecting the times to the reasonable allocation of resources business, to maximize the creation of social wealth, become the cornerstone of the survival and development of enterprises in the information age ${ }^{[3]}$. SAP (System Applications and Products) is the software name of SAP's product-enterprise management solution and has the absolute leading position in the global ERP market. About $80 \%$ of the Fortune 500 companies use SAP software.

In the final analysis, the competition of enterprises is the competition of talents. ERP talent is the most important asset of the enterprise, the core and soul of the process of enterprise information construction, and it is also the crucial foundation of industrial development. Therefore, to establish an excellent team of ERP talent is imperative.

Based on the integration of industry-university-research, mode of cultivating innovative talents with the requirements of "excellent foundation, strong ability and focus on application", adhering to the characteristics of ERP/SAP, through the virtuous interaction of the integration of industry-university-research, to build up mode of cultivating innovative talents for information management major. 


\section{Build up the mode of information innovation talent development based on industry needs}

Colleges and universities actively explore the industry-university-research cooperation model of enterprise informatization personnel training, it is necessary to closely follow the industry trend of development, based on the demand of enterprise information talents to reverse the information application personnel training mode ${ }^{[4]}$, establish "internationalization, practical, personalized" Training objectives and realizing the mutual supplement of student training, teacher training, school-enterprise cooperation and continuous improvement through the strategic direction of "leapfrog development and open innovation"; and to establish a talent training that meets the needs of the informatization industry innovation system to realize the reform and innovation of knowledge structure for innovation-oriented talents; establish a collaborative and interactive training system for internal and external applications based on industry-university-research cooperation; build a multi-dimensional and operational cooperation and standardization management structure and process of industry-university-research; The resource sharing, performance evaluation and feedback mechanism of cooperation between industry-university-research, so as to realize the innovation of talent cultivation mode ${ }^{[5]}$.

\section{Innovative talent training objective and path facing ERP/SAP features}

Based on the collaborative integration analysis of information management specialty and extensive research of stakeholders, based on the real background of enterprises, colleges and universities integrate the resources of SAP partners and integrate the urgent needs of the society for ERP talents. Focusing on ERP/SAP business solutions, teaching staffing, curriculum setting, experimental environment, practical training methods and employment channels constitute an organic whole, and a "ERP/SAP" as the representative of the school-enterprise cooperation and integration of professional curriculum system, enterprise projects, cases into the curriculum, timely Track industry and industry progress, integrate new theories, new technologies, new tools, new products and new applications into curriculum/project teaching so as to realize the practical teaching of integration of production and teaching so as to solve the problem of how students should acquire knowledge, abilities and attitudes and train them Master the modern management theory, modern information technology, with information management and information systems such as SAP application and development capabilities of application of advanced specialized personnel. The path of cultivating information innovation talents with SAP is shown in Fig. 1.

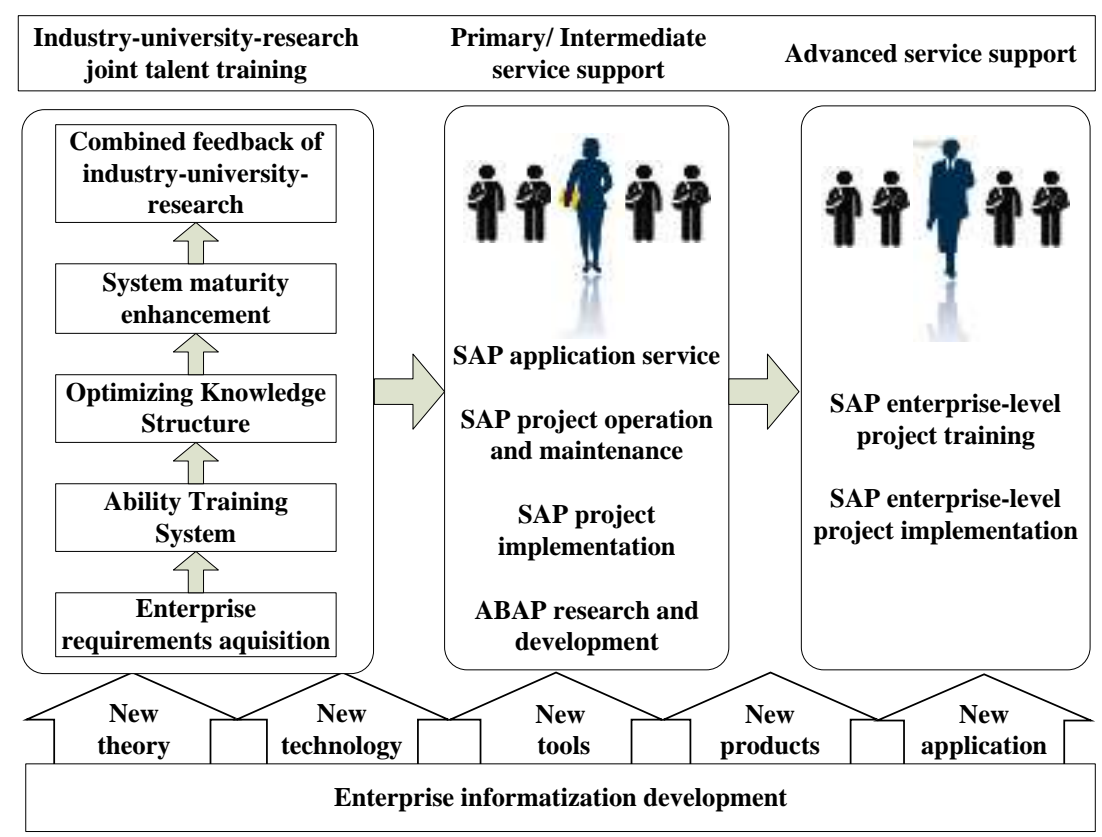

Figure 1. Innovative talents training for information management with SAP 


\section{School-enterprise integration of professional construction innovation and interactive mechanism}

Schools should be based on the application of professional skills and basic quality training as the main line, expanding the need to learn, to learn midwifery, to promote industry-university-research of the cycle of development system, production, research institutes to achieve a virtuous interaction mechanism $^{[6]}$.

What to learn determined by what to be needed, to meet the requirement of customized business

Both schools and enterprises have achieved mutual benefits and promoted common development through cooperation in teaching, building experiment and training bases and other forms. Through business and social surveys, PULL information can be used to obtain timely information about the demand for talent from enterprises. Through two-way exchange of information, we can understand the needs of each school-enterprise and understand the win-win cooperation model and act accordingly. In the flexible management give full play to specialty, forming a "school in the enterprise", "enterprises in the school" pattern ${ }^{[7]}$. Through business cooperation in curriculum teaching, student assignments and teaching resources to build, to achieve multi-win-win situation and promote common development.

The enterprise practice base into a practical platform for sharing, facing other schools, enterprises, research institutions open. First of all, relevant professional schools and research institutes should be included in the sharing system first, and then a multi-enterprise, multi-institution and multi-institution organization should jointly build a corporate practice base based on the sharing mechanism. The construction of shared platform includes the construction of networked sharing practice and scientific research information platform, and the practical resources, scientific research and personnel information of online SAP practice system, project and case are provided to social enterprises, other institutions and research institutes through the network platform. At the same time, the benefits of outsourcing services and education and training obtained from the base share platform will also be rationally allocated to the jointly-funded organizations and the traditional "consumable" practice base will be changed into an "operational" base of practice as shown in Fig. 2.

Schools and enterprises should deepen the connotation of training base construction through training field expansion, equipment renewal, training of teaching staff, content reform of training programs and improvement of social training services. Schools and enterprises should integrate teaching, training and scientific research as a whole, to expand the social service function, set the external training, technical advice, outsourcing services as a whole, to achieve the practice of multi-functional training base construction goals.

Learning facilitates production, to cultivate innovative and applied talents

Schools around the professional training objectives, business projects, cases into the curriculum system, the relevant professional certification into the curriculum system ${ }^{[8]}$. Professional to build a "ERP/SAP" as the representative of the cooperation between production and teaching information system of professional courses, make full use of SAP's powerful information technology training and R \& D platform, in the theoretical courses and practical courses SAP knowledge system will be mastered, to develop "ERP/SAP "information talent. In project training and graduation project, the real case of enterprises is directly used to carry out the project implementation and project research, which not only enables students to gain access to the latest technologies in the market, but also helps enterprises to improve economic efficiency.

\section{Production facilitates learning, to promote industry-university interaction and cooperation}

Schools can use flexible mechanisms such as business mentors and teacher assignments to promote industry-academia interaction and make the industry a base for training high-skilled personnel, training "double-qualified" teachers and transforming high-tech achievements. Actively cooperate with the enterprise, through the teacher to the enterprise attachment exercise, improve teachers' practical ability. Formulation and improvement of an industry-university-research cooperation process, as shown in Fig. 3. 


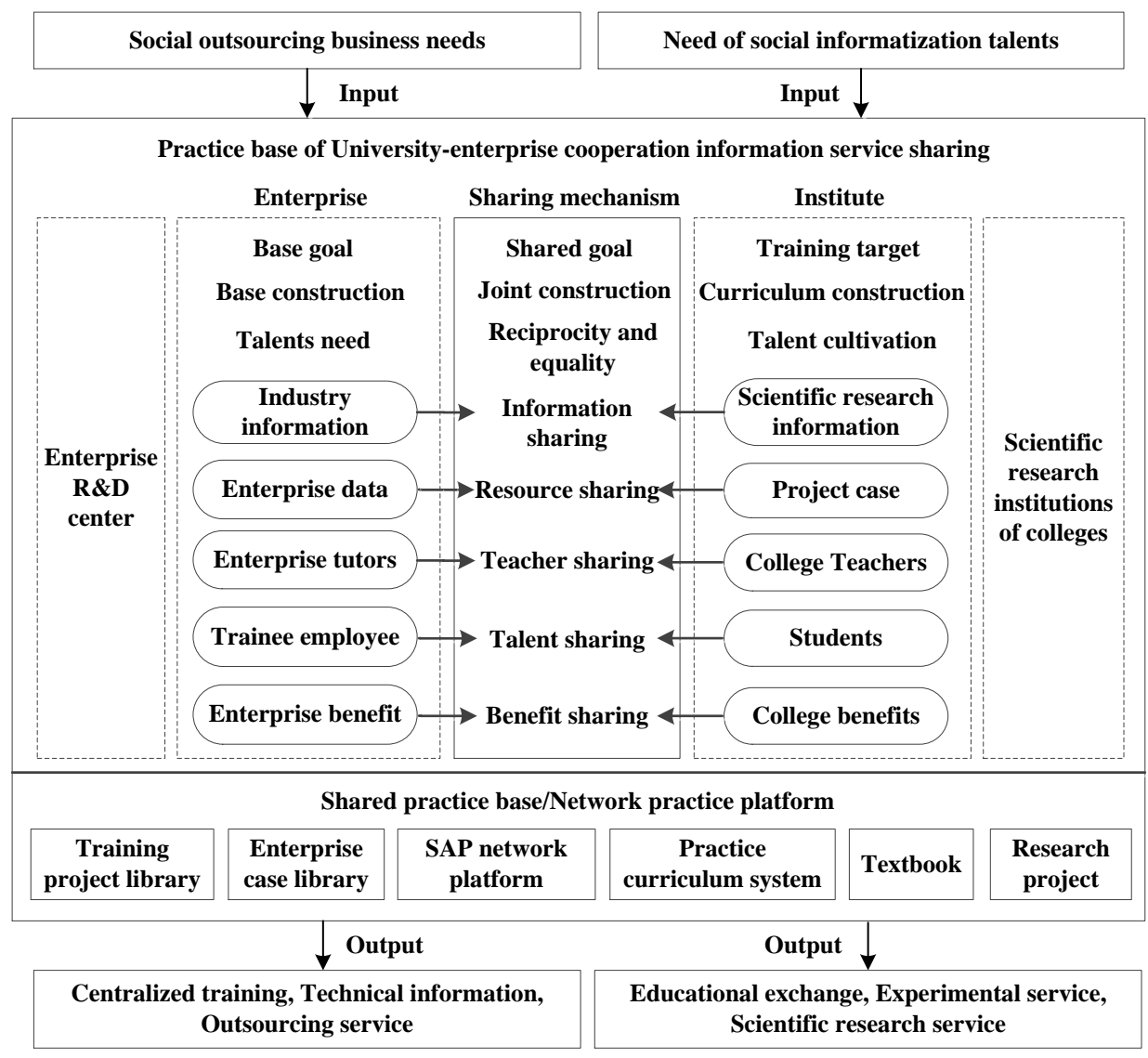

Figure 2. Practice base of operating-type development sharing mechanism

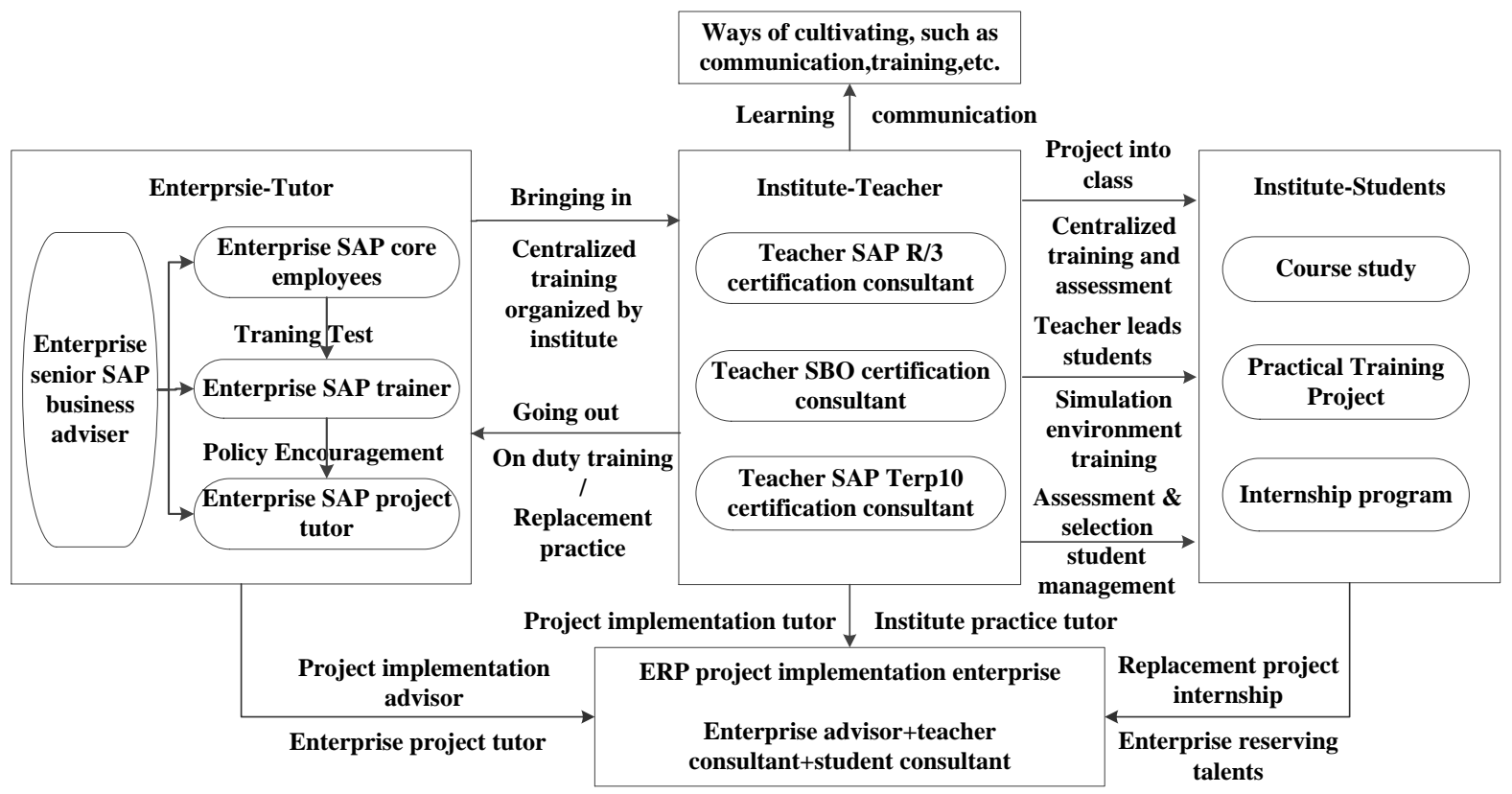

Figure 3. School-enterprise cooperation standardization member selection process

The practical education base starts with the training of application-oriented informatization talents, captures the demand of enterprise informatization talents, standardizes the member selection process, and delivers application-oriented talents who provide R\&D and implementation services of ERP/SAP solutions to enterprises through student selection and training. Through effective management mechanisms and processes, the cooperation between school and enterprise can be planned in advance, controlled in events, and checked and summarized afterwards. Through the cooperation between school 
and enterprise, it not only can train a large number of professional teachers, enhance teachers' practical skills, strengthen the linkage between enterprises and professions, but also cultivate a large number of informatization application talents. At the same time, the use of flexible mechanisms to promote interaction between production and learning, so that students really do secondary school, learning from, and effectively enhance students' practical skills.

Production promoted through the research, to realize the depth of industry-university integration

Schools and enterprises signed a horizontal project agreement, access to teaching resources through the teaching of technical resources sponsorship. At the same time, we should strengthen communication and cooperation with enterprises, carry out researches on scientific research projects, develop practical technologies, improve the science and technology level of the institutes, and strive to achieve a win-win situation for both schools and enterprises and enable the interaction of production, study and research cycles $^{[9]}$. Training mode, teacher training, construction of practice bases, transformation of internship organizations and scientific and technological achievements, training for the society, and many other aspects to obtain substantial achievements in research and development ${ }^{[10]}$.

\section{Summary}

The cultivation of college students has become the most concerned issue nowadays in colleges and universities all over the country, and how to cultivate them is the core issue. The co-innovation model of industry-university-research puts forward an effective training mode for information personnel training. Through sincere cooperation between schools and enterprises, students can build a smooth internship channel, comprehensively cultivate the overall quality of students, improve the effectiveness of teaching in colleges and universities, improve students 'professional skills in adapting to the society, adapting to market changes and enterprise needs, and cultivating students' Demand and business development of high-quality personnel requirements.

\section{References}

[1] Information on https://www.wendangwang.com/doc/e1010367ca47a2784bc9eaec/2

[2] Y.S. Liu: Construction Enterprise Management (Beijing Jiaotong University press, China, 2014), pp. 283-320.

[3] Z.Y. Du and X.G. Wang: Enterprise Resource Planning Application Course (Huazhong University of Science and Technology Press, China, 2005), pp. 1-12.

[4] C.L. Huang, M.H. Zhang and H.Y. Tian, School-Enterprise Cooperation Mode for IT Oriented Talents Training, Computer Education, 13 (2012) 84-86.

[5] X.K. Li, An Overview of the Mode of Foreign Industry-University-Research Cooperation and Its Enlightenment to the Teaching of Colleges and Universities in China, Modern Enterprise Education, 10 (2014) 172.

[6] Y.Y. Zhu, Research on the Construction and Practical Application of the Coupled System of Production, Experimental Technology and Management, 12 (2012) 149-151.

[7] D.C. Li and Y.J. Shao, Theoretical and Practical Exploration of the Training Mode for Excellent Engineers (HeFei University of Technology Press, China, 2013).

[8] X.Y. Wang and D. Wu, Research on Integrated Curriculum System of Applied Talents Based on CDIO Concept, China Education Innovation Herald, 1 (2013) 95-96.

[9] D.S. Zeng, The Way and Evaluation System of the Deep Integration for School and Enterprise in Higher Vocational Colleges, Consume Guide, 4 (2011) 69-70.

[10] C.X. Yan and K.J. Bao, The Establishment and Effect of the Practice Teaching System of "Two Cycles and Combination of Virtual Reality", Experimental Technology and Management, 12 (2012) 145-148. 